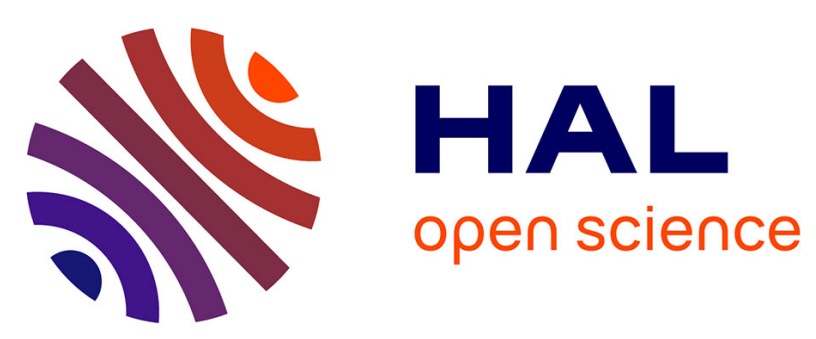

\title{
Positron Annihilation Measurements on Nuclear Reactor Pressure Vessel Steels
}

L. van Hoorebeke, J. van de Velde, D. Segers, L. Dorikens-Vanpraet, S. Simula

\section{To cite this version:}

L. van Hoorebeke, J. van de Velde, D. Segers, L. Dorikens-Vanpraet, S. Simula. Positron Annihilation Measurements on Nuclear Reactor Pressure Vessel Steels. Journal de Physique IV Proceedings, 1995, 05 (C1), pp.C1-171-C1-175. 10.1051/jp4:1995120 . jpa-00253556

\section{HAL Id: jpa-00253556 https://hal.science/jpa-00253556}

Submitted on 1 Jan 1995

HAL is a multi-disciplinary open access archive for the deposit and dissemination of scientific research documents, whether they are published or not. The documents may come from teaching and research institutions in France or abroad, or from public or private research centers.
L'archive ouverte pluridisciplinaire HAL, est destinée au dépôt et à la diffusion de documents scientifiques de niveau recherche, publiés ou non, émanant des établissements d'enseignement et de recherche français ou étrangers, des laboratoires publics ou privés. 


\title{
Positron Annihilation Measurements on Nuclear Reactor Pressure Vessel Steels
}

L. van Hoorebeke, J. van de Velde, D. Segers*, L. Dorikens-Vanpraet* and S. Simula*,(1)

SCK-CEN, Reactor Materials Research Unit, Boeretang 200, $2400 \mathrm{Mol}$, Belgium

* RUG, Dep. of Subatomic and Radiation Physics, Proeftuinstraat 86, 9000 Gent, Belgium

\begin{abstract}
Positron Annihilation Spectroscopy is a valuable microscopic method to study radiation damage in nuclear reactor pressure vessel steels. At SCK•CEN, a new positron lifetime setup, suited to measure positron lifetimes in irradiated steel, is being constructed. The particularity of this setup is that the prompt count rate originating from the induced ${ }^{60} \mathrm{Co}$-activity in the steel is highly reduced. Some preliminary results obtained for unirradiated SA-508 steel are discussed.
\end{abstract}

\section{INTRODUCTION}

The reactor pressure vessel is one of the main components of a pressurized nuclear power plant. Typical vessel conditions during operation are a temperature around $300{ }^{\circ} \mathrm{C}$ and a pressure inside the vessel of roughly 150 bar. For safety assessment aspects, the mechanical properties of the material have to be considered. During service operation, however, these mechanical properties change, mainly due to irradiation embrittlement of the vessel steel. Therefore, surveillance programs are being used to evaluate the changes and to guarantee safe operation of the plant.

The steel embrittlement process has been extensively studied on a macroscopic scale by means of mechanical tests, mainly Charpy-V notch and tensile tests [1]. It turns out that the embrittlement process is a very complicated process that depends on many parameters such as the chemical composition, the irradiation temperature, the irradiation flux and fluence,.... A number of semi-empirical laws, based on the macroscopic data, have been established but unfortunately these laws are never completely consistent with all data and do not yield the wanted accuracy.

A good fundamental understanding of the microscopic processes leading to irradiation embrittlement of steel would therefore be very valuable. To study these microscopic processes, microscopic research techniques have to be used. At $\mathrm{SCK} \bullet \mathrm{CEN}$, it is intended to use positron annihilation spectroscopy in combination with other, complementary methods such as, e.g., TEM, Internal Friction and Mössbauer effect. The complexity of the embrittlement processes calls indeed for the use of several methods. The great value of positron annihilation for this research is that this method is considered to be a good tool for obtaining information about changes in vacancy-type defects. It is generally accepted that the formation of vacancy-type defects contributes to steel embrittlement. 


\section{POSITRON ANNIHILATION LIFETIME MEASUREMENTS ON IRRADIATED STEEL}

Positron annihilation lifetime measurements on irradiated steel are severely complicated by the induced ${ }^{60} \mathrm{Co}$-activity present in the steel. ${ }^{60} \mathrm{Co}$ emits two coincident gamma rays that produce "false" triggers in a classical lifetime setup, leading to a very disturbing prompt peak in the lifetime spectrum (Figure 1). This prompt peak hampers the analysis of the lifetime spectrum and, if its magnitude becomes too large, it can even make the analysis impossible. Several ways to tackle this problem are described in the literature. The most obvious way is of course to reduce the size of the steel samples as much as possible, while making sure that all positrons are stopped in the samples (e.g., [2, 3]). In addition, one can perform two measurements for each pair of samples, one with the positron source and one without the source (e.g., [4]). The difference spectrum then yields the net positron lifetime spectrum, albeit with reduced statistical accuracy. However, this procedure does not always work well [5]. Analysis of lifetime spectra containing a ${ }^{60} \mathrm{Co}$-contribution can be attempted by excluding the peak-region as demonstrated in [5], but utmost care must be taken in the interpretation of the data.

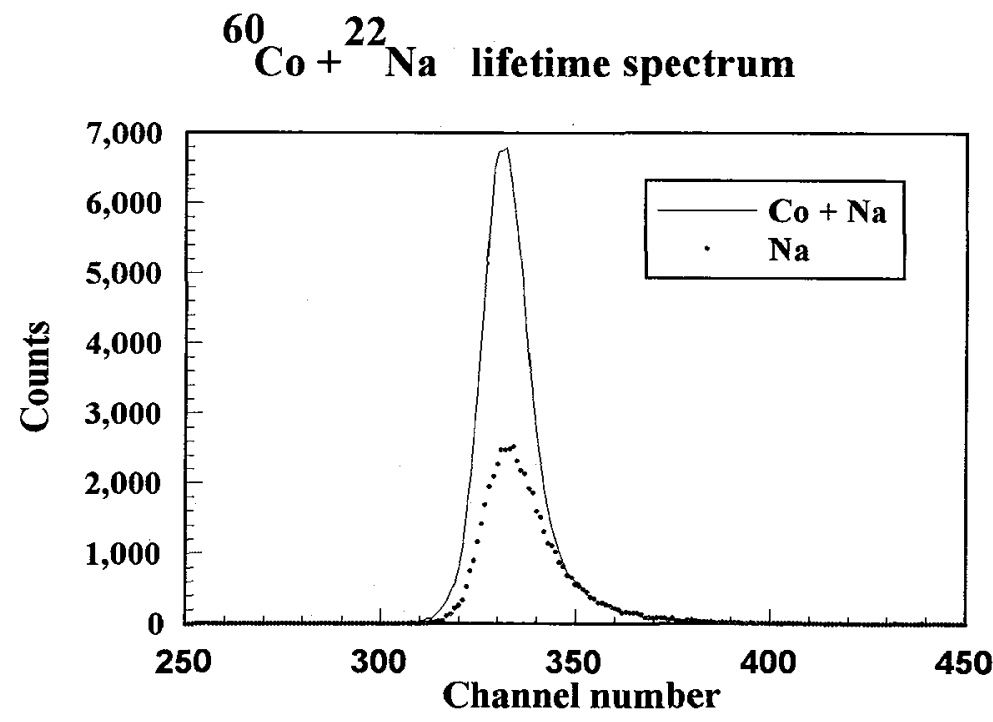

Figure 1.: Lifetime spectrum recorded with and without ${ }^{60} \mathrm{Co}$ between the detectors, using a classical two-detector setup. These spectra are only illustrative, and do not contain enough counts to allow a good quality data analysis.

\section{THREE-DETECTOR LIFETIME SETUP}

It is clear that the most elegant solution for the ${ }^{60} \mathrm{Co}$-problem would be to prevent that any prompt counts are obtained in the lifetime spectnum. Therefore, at SCK•CEN, a new positron lifetime setup is being constructed, based on three photon detectors instead of two (Figure 2). The basic advantage of this setup is that it is possible to distinguish between ${ }^{22} \mathrm{Na}$-events (the positron source) and ${ }^{60} \mathrm{Co}$-events by requiring a triple coincidence for accepting counts in the lifetime spectrum. Indeed, only when dealing with a real annihilation of a positron, three photons are present (the start-gamma and two $511 \mathrm{keV}$ gamma rays). Such a setup should make possible to perform measurements on irradiated steel without being hampered by the ${ }^{60} \mathrm{Co}$-activity. To obtain an acceptable count rate using a triple coincidence requirement, highly efficient $\mathrm{BaF}_{2}$-scintillators (1" thick and $1.5^{\prime \prime}$ diameter) are used. Moreover, by 
switching from a triple to a double coincidence requirement, a very efficient classical lifetime setup is obtained, suitable for performing measurements on non-active samples. To prevent saturation of the photomultiplier (PM) pulses at rather high ${ }^{60} \mathrm{Co}$ activity $(2 \mathrm{MBq})$ while also maintaining a good time resolution, it proved necessary to apply dynode timing. Since XP2020Q PMs and ORTEC 269 PM bases are used, the signal is taken from the eighth dynode. The long $\mathrm{BaF}_{2}$ component is filtered out and the "clean" inverted signal is fed into a fast Lecroy 612AM PM amplifier before being used as input for the CFDDs. Dynodes 10, 11 and 12 are kept at the same voltage as dynode 9, which means that the stages drawing the highest current are deactivated. This prevents saturation. Deactivating the last PM stages in case of dynode timing has been applied before (e.g., [9,10]). With a $200 \mathrm{kBq}{ }^{60} \mathrm{Co}$ source and energy windows suited for lifetime measurements, a time resolution of $260 \mathrm{ps}$ can be obtained (the time resolution is of course exactly the same in the two and in the three detector mode). Using the $2 \mathrm{MBq}{ }^{60} \mathrm{Co}$ source, the time resolution degrades to $290 \mathrm{ps}$, which is due to the presence of the long $\mathrm{BaF}_{2}$ component. The goal is to keep the time resolution below 300 ps during actual measuring situations by adjusting detector-source distances to keep detector count rates at an acceptable level.

When switching from the double to the triple coincidence mode, the count rate in the lifetime spectrum is reduced by a factor of 5 for ${ }^{22} \mathrm{Na}$, while it is reduced by about a factor of 500 for ${ }^{60} \mathrm{Co}$. Using a $50 \mathrm{kBq}{ }^{22} \mathrm{Na}$ test source, 2 counts per second are obtained in the triple coincidence mode. A $1.5 \mathrm{MBq}$ ${ }^{22} \mathrm{Na}$ source will probably be used for the actual measurements. For more details about this setup see [6].

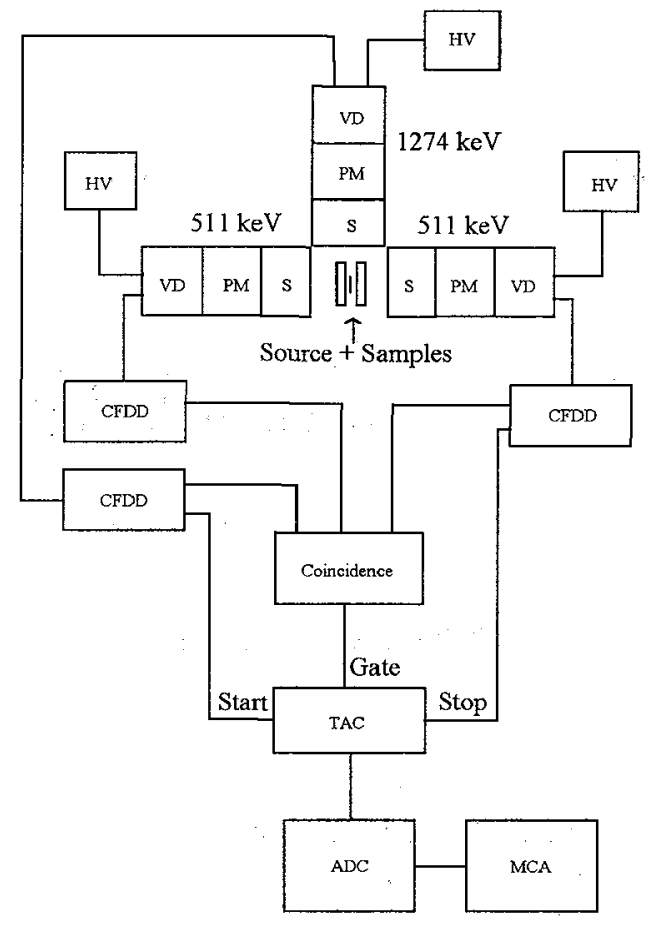

Figure 2.: schematic drawing of the new SCK CEN three-detector setup. S:Scintillator; PM: Photomultiplier; VD: voltage divider; CFDD: Constant fraction differential discriminator; HV: High Voltage; TAC: Time to amplitude convertor; ADC: Analog to digital convertor; MCA: Multi-channel analyzer. 


\section{PRELIMINARY RESULTS}

The interpretation of positron annihilation data obtained on very impure materials such as steel is far from evident. In the positron laboratory of the RUG, some surveying measurements have been performed on unirradiated SA-508 RPV steel using the RUG lifetime setup (280 ps time resolution). Isochronal annealing curves have been measured on samples in the as-received condition, and afterwards these samples were deformed and the curve was remeasured. A typical isochronal annealing result is shown in Figure 3, depicting the mean positron lifetime as a function of the annealing temperature for deformed weld material. The decomposition of the lifetime spectra into more components was not successful, which is not unusual for a complex material such as steel (e.g., [3]). The samples were annealed for 60 min at each temperature, and the measurements took place at room temperature. A second deformation gave rise to a similar result. Base and weld material show essentially the same behaviour.

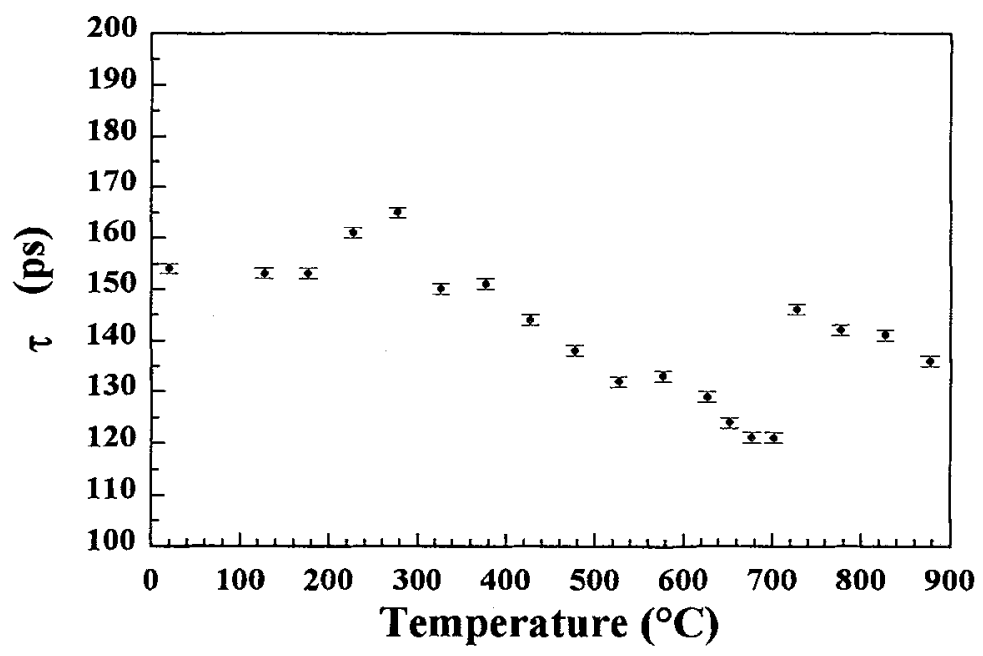

Figure 3. Mean positron lifetime as a function of successive isochronal annealings (60 min) at different temperatures for $25 \%$ deformed SA-508 weld material.

The annealing behaviour of the steel is clearly complicated. The mean positron lifetime shows a maximum around $300^{\circ} \mathrm{C}$, while at higher temperatures the lifetime decreases continuously to a minimum (very close to the bulk value of $\mathrm{Fe}, 110 \mathrm{ps}$ [11]) at around $700^{\circ} \mathrm{C}$. The behaviour of the mean lifetime between $400^{\circ} \mathrm{C}$ and $600^{\circ} \mathrm{C}$ is rather similar to the behaviour observed in the isochronal annealing of deformed iron [7], where the observed effect was attributed to the annealing of dislocations introduced by the deformation. Above $700^{\circ} \mathrm{C}$ there is a sudden rise of the mean lifetime. A similar behaviour of the lifetime parameters in steel around $700^{\circ} \mathrm{C}$ has been observed elsewhere [2] and was attributed to the $\alpha-\gamma$ phase transition taking place in the steel at around $720^{\circ} \mathrm{C}$. The probable cause is that while the samples cool down from above the transition temperature to below this temperature, new defects are created in the matrix, giving rise to the increased mean lifetime measured at room temperature. This behaviour is observed for samples of the base and most of the weld material. For some weld material samples, however, the lifetime remains around $120 \mathrm{ps}$ when annealed above $700^{\circ} \mathrm{C}$. At this moment this can only be attributed to inhomogeneity of the weld material. The comparison of isochronal annealing results on non-irradiated and irradiated steels (e.g., $[2,3,8]$ ) can yield valuable information about changes introduced in the steel by radiation damage. 
The results given in this paper are preliminary and reflect the early stage of development of our research at the time of the Workshop. Further results obtained since then will be reported elsewhere [6].

\section{CONCLUSIONS}

Positron annihilation spectroscopy is a valuable method for studying radiation damage in nuclear reactor pressure vessel steels. The three-detector lifetime setup being built at SCK•CEN will allow the measurement of positron lifetimes in irradiated steels without being hampered by the ${ }^{60} \mathrm{Co}$-activity. The first tests of this setup are encouraging. The comparison of measurements on non-irradiated and irradiated steel will yield information on the importance of vacancy-type defects in the irradiation embrittlement process. However, steel is a very complex material and, as such, the interpretation of the positron data is not an easy task. In combination with other microscopic research methods, positron annihilation will help to obtain a better understanding of radiation damage in steel.

\section{REFERENCES}

[1] Metals Handbook, Vol 8, Ninth edition, American Society for Metals, 1985, pp. 17-51, pp. 261-268

[2] C.Lopes Gil, A.P.De Lima, N.Ayres De Campos, J.V.Fernandez, G.Kögel, P.Sperr, W.Triftshäuser and D.Pachur, J.Nucl.Mater. 161(1989)1

[3] R.Pareja, N.De Diego, R.M. De La Cruz and J. Del Rio, Nuclear Technology 104(1993)S2

[4] M.Valo, R.Krause, K.Saarinen, P.Hautojärvi and J.Russel Hawtorne, "Irradiation Response and Annealing Behavior of Pressure Vessel Model Steels and Iron Ternary Alloys Measured with Positron Techniques", Effects of Radiation on Materials: 15th International Symposium, ASTM STP 1125, R.E. Stoller, A.S.Kumar and D.S. Gelles, Eds., American Society for Testing and Materials, Philadelphia, 1992, pp. 172-185

[5] G.H.Dai, P.Moser and J.C. Van Duysen, Materials Science Forum Vols. 105-110(1992)pp. 941-944

[6] L.Van Hoorebeke et al., to be submitted to Nucl. Instr. and Meth. in Phys. Res. A

[7] P.Hautojärvi and A.Vehanen, Appl. Phys. 11(1976)191

[8] G.Brauer, L.Liszkay, B.Molnar and R.Krause, Nuclear Engineering and Design 127(1991)47-68

[9] B.Bengtson and M.Moszynski, Nucl.Inst. and Meth. 204(1982)129-140

[10] J.De Vries and F.E.T.Kelling, Nucl. Instr. and Meth. in Phys. Res. A262(1987)385

[1 1] P.Hautojärvi, L.Pöllänen, A.Vehanen and J.Yli-Kaupila, J.Nucl.Mater. 114(1983)250-259 